\title{
Anti-angiogenic therapies in the management of glioblastoma
}

\author{
Jessica D. Schulte ${ }^{1}$, Manish K. Aghi ${ }^{1}$, Jennie W. Taylor ${ }^{1,2}$ \\ ${ }^{1}$ Department of Neurological Surgery, University of California, San Francisco, CA, USA; ${ }^{2}$ Department of Neurology, University of California, San \\ Francisco, CA, USA \\ Contributions: (I) Conception and design: JD Schulte, JW Taylor; (II) Administrative support: None; (III) Provision of study materials or patients: \\ None; (IV) Collection and assembly of data: JD Schulte; (V) Data analysis and interpretation: All authors; (VI) Manuscript writing: All authors; (VII) \\ Final approval of manuscript: All authors. \\ Correspondence to: Jessica D. Schulte, MD, PhD. Department of Neurological Surgery, University of California, 400 Parnassus Avenue A808, San \\ Francisco, CA 94143, USA. Email: Jessica.Schulte@ucsf.edu.
}

\begin{abstract}
Angiogenesis is a central feature of glioblastoma (GBM), with contribution from several mechanisms and signaling pathways to produce an irregular, poorly constructed, and poorly connected tumor vasculature. Targeting angiogenesis has been efficacious for disease control in other cancers, and given the (I) highly vascularized environment in GBM and (II) correlation between glioma grade and prognosis, angiogenesis became a prime target of therapy in GBM as well. Here, we discuss the therapies developed to target these pathways including vascular endothelial growth factor (VEGF) signaling, mechanisms of tumor resistance to these drugs in the context of disease progression, and the evolving role of anti-angiogenic therapy in GBM.
\end{abstract}

Keywords: Brain tumor; glioblastoma (GBM); angiogenesis; vascular endothelial growth factor (VEGF); resistance; radiation necrosis

Submitted Feb 03, 2020. Accepted for publication Mar 13, 2020.

doi: $10.21037 /$ cco.2020.03.06

View this article at: http://dx.doi.org/10.21037/cco.2020.03.06

Glioblastoma (GBM) is the most aggressive and unfortunately most common, malignant primary brain tumor, with a median survival of $10-31$ months depending on age at diagnosis, extent of resection, treatment and molecular prognostic factors (1-4). Angiogenesis is a central feature of GBM, with microvascular glomeruloid proliferation requisite for histological diagnosis $(5,6)$. Endothelial cells comprise the tumor blood vessels, facilitating delivery of nutrients and oxygen. In addition, endothelial cells directly support glioma progenitor cell proliferation through intercellular signaling pathways, contributing to tumor growth and resilience (7).

\section{Mechanisms of angiogenesis}

Angiogenesis in gliomas involves various mechanisms: co-option of preexisting vessels (8); de novo angiogenesis through extension of nearby vessels (9); differentiation of bone marrow-derived endothelial progenitors (10); multiplication of vessels through splitting of existing vessels (also known as intussusception) (11); and vascular mimicry by glioma stem cells that form luminal cylinders resembling vessels (12-15).

Angiogenesis is regulated by intricate and overlapping signaling pathways, which involve both hypoxia-dependent and -independent processes. In hypoxic environments, hypoxia inducible factor 1 subunit alpha $(H I F-1 \alpha)$ is upregulated, driving expression of pro-angiogenic genes such as vascular endothelial growth factor $(V E G F)$. VEGF protein binds to its receptor VEGFR and activates additional growth factors that mediate endothelial sprouting, migration, and endovascular permeability. Hypoxia also induces matrix metalloproteinase (MMP) production that mediates stromal disintegration and endothelial migration $(16,17)$. Angiopoietin $1(A N G 1)$ and $A N G 2$ have a complicated interplay, but work together to help formalize these primitive vessels. ANG1 protein stabilizes vessels by facilitating cell interactions that support vasculature integrity (18). The role of ANG2 depends on the presence or absence of VEGF. When VEGF is present, 
ANG2 acts via tyrosine kinase with immunoglobulin-like and EGF-like 1 (TIE1) receptors to promote angiogenesis and stimulate the migration and differentiation of endothelial cells, through Notch and ephrin-A2 signaling, respectively (19-22). When VEGF is absent, ANG2 acts via TIE2 receptors to destabilize blood vessels, causing endothelial apoptosis and vessel regression (19). In low nutrient environments, $V E G F$ can be upregulated through peroxisome-proliferator-activated receptor- $\gamma$ coactivator$1 \alpha(P G C-1-\alpha)$ independently of hypoxia (23). In addition, several different gene mutations that are common in gliomas, including platelet-derived growth factor $(P D G F)$, epithelial growth factor receptor (EGFR), p53 (TP53), $\mathrm{RB}$ transcriptional corepressor 1 (RB1), von HippelLindau tumor suppressor $(V H L)$ and phosphate and tensin homolog (PTEN), all stabilize HIF-1 $\alpha$ causing subsequent upregulation of $V E G F(24,25)$.

In addition to $V E G F$-related actions on angiogenesis, stromal cell-derived factor 1 protein (SDF-1, also known as C-X-C motif chemokine ligand 2, CXCL2), and its receptor CXCR4 (C-X-C motif chemokine receptor 4), also recruit bone marrow-derived progenitors from the circulation into the tumor that subsequently differentiate into endothelial cells and pericytes (26-28). Other growth factor pathways including fibroblast growth factor $(F G F)$, phosphoinositide 3-kinase (PIK3), PDGF, and transforming growth factor $\beta 1$ (TGFB1), mediate angiogenesis through a combination of mechanisms that regulate $V E G F$ expression, stimulate endothelial cell proliferation, and regulate expression of proteases implicated in vessel dissolution and migration (29-32). As these processes unfold, the tumor vasculature manifests as irregular, poorly constructed, and poorly connected vessels (33). This disorganized and leaky system creates spatiotemporal heterogeneity in tumor oxygenation that may impact the development and expansion of the tumor's genetic subclone populations.

\section{Therapeutic strategies targeting angiogenesis}

Targeting angiogenesis through VEGF blockade and other mechanisms has been efficacious in other cancers. In addition to triggering tumor cell death via deprivation of oxygen and nutrients, targeting angiogenesis may lead to the transient normalization of the tumor vasculature and improved uptake of cytotoxic chemotherapy (34). In addition to observations that GBM is a highly vascularized tumor, several studies correlated $V E G F$ expression with glioma grade and prognosis $(16,35,36)$. Thus, angiogenesis became a prime target of therapy in GBM as well.

While there are many inhibitors targeting different parts of the angiogenesis cascade, the only approved treatment in the United States (US) is bevacizumab, a recombinant human monoclonal antibody that binds to and sequesters VEGF, preventing activation of its receptors. In 2004, it was first FDA-approved for treatment of advanced colorectal cancer, where it reduced microvascular density and blood perfusion (37). The first clinical trials of bevacizumab in GBM were in recurrent disease in the "AVF3708g/ BRAIN" and "NCI 06-C-0064E" phase II trials. In these trials, bevacizumab monotherapy or combination therapy with irinotecan, demonstrated objective response rates (28$40 \%$ ) and progression-free survival at 6 months (PFS6) of $40-50 \%$ that were markedly improved compared to higher historical controls, but no improvement in overall survival (OS) (38-40). These studies led to conditional accelerated FDA approval of bevacizumab in recurrent GBM in 2009 , approved as monotherapy given the added toxicity in the combination arm $(38,39)$. The phase III European Organization of Research and Treatment of Cancer (EORTC) 26101 trial in recurrent GBM investigated lomustine with or without bevacizumab, and combination therapy also demonstrated improvement in PFS (1.5 to 4.2 months) but no change in OS (41). Both the AVF3708g and EORTC 26101 trials demonstrated reduced reliance on steroids. In EORTC 26101, more patients on bevacizumab were able to completely stop steroids than patients in the control arm (23\% vs. 12\%). Based on the results of this trial, bevacizumab received full approval for treatment of recurrent GBM in 2017.

Bevacizumab was also investigated in newly diagnosed GBM in two large randomized, double-blinded, phase III trials-Radiation Therapy Oncology Group (RTOG) 0825 and AVAglio. Both trials demonstrated an improvement in PFS by 3.4-4.4 months with addition of bevacizumab to standard temozolomide and radiation, but no improvement in OS $(42,43)$.

Aflibercept, also known as VEGF trap, is a recombinant fusion protein that binds to circulating VEGF-A and VEGF-B, as well as placenta growth factor (PGF), and inhibits binding to VEGF receptors and downstream signaling. A phase II trial in recurrent malignant glioma demonstrated PFS6 of $7.7 \%$ in GBM, however the study was notable for high dropout attributed to significant toxicities (44).

Tyrosine kinase inhibitors (TKIs) are small molecules that target one or many tyrosine kinase receptors, including 
VEGFR, EGFR, PDGFR, and FGFR. Sunitinib and sorafenib both target VEGFR in addition to c-Kit and PDGFR, and are shown to improve survival in other cancers including metastatic renal and hepatic cell carcinoma $(45,46)$. However, a phase II trial looking at sunitinib monotherapy in bevacizumab-naïve and -resistant recurrent GBM demonstrated no improvement in PFS or OS (47). Sorafenib was tested in a phase I trial of recurrent GBM with modest effect on outcomes (median PFS 7.9 months and OS 17.8 months), but several dose-limiting toxicities (48). Phase III trial of cediranib, another inhibitor of VEGFR, c-Kit and PDGFR, versus lomustine versus combination failed to meet its primary endpoint of PFS in recurrent GBM (49). Enzastaurin, which targets the protein kinase $\mathrm{C}$ and $P I 3 K / A K T$ serine/threonine 1 pathways, also failed to meet its primary endpoint of improvement in PFS or OS in a phase III trial in recurrent GBM comparing enzastaurin versus lomustine (50).

Unfortunately, targeting other components of angiogenesis has also demonstrated limited efficacy. Trebananib (AMG386), a peptide fused to the Fc immunoglobulin protein, inhibits ANG1 and ANG2 ligands from interacting with the TIE2 receptor. Phase II study of trebananib versus combination with bevacizumab in recurrent GBM showed no improvement compared to historical OS of bevacizumab monotherapy (51). Cilengitide, an antagonist of integrins $\alpha v \beta 3$ and $\alpha v \beta 5$ that mediate vascular stability, did not improve PFS or OS in combination with standard therapy for newly diagnosed GBM (52). In addition to the treatments discussed above, there are many additional clinical trials using medications targeted toward angiogenesis, in different phases of development (Table 1).

\section{Pathways of resistance}

Despite the biologic rationale and early promise of antiangiogenic therapies, no agent in isolation or in combination has yet demonstrated an improvement in survival in GBM. Mechanisms of resistance are multifactorial and involve (I) upregulation of $V E G F$-independent angiogenesis; alternative methods of vasculogenesis including (II) recruitment of bone marrow-derived progenitors, (III) vascular mimicry and (IV) vessel co-option; (V) tumor cell autophagy; and (VI) tumor cell migration away from the tumor center and invasion into surrounding brain tissue (Figure 1). In addition to these pathways, there is some data that tumors treated with TKIs may acquire mutations in tyrosine kinase domain that dampen the response to TKIs, as seen with EGFR inhibitors gefitinib and erlotinib (90).

Downregulation of $V E G F$ leads to upregulation of other proangiogenic pathways, including $P D G F$, $F G F$, phosphatidylinositol glycan anchor biosynthesis class $\mathrm{F}(P l G F)$, hepatic growth factor $(H G F) / c-M E T$ protooncogene, $A N G 1, A N G 2$, delta4-notch (DLL4Notcb), and interleukins $(12,91,92)$. Hypoxia resulting from treatment with VEGF inhibitors upregulates $H I F-1 \alpha$, which in turn increases expression of $A N G 2$ (93). $F G F$, which is involved in developmental and oncologic angiogenesis, may mediate resistance to VEGF inhibitors such as cediranib $(94,95)$. In addition to regulation of $F G F$ and ephrin signaling pathways, the DLL4-Notch pathway may also mediate resistance to VEGF inhibition by stabilization of larger vessels (96).

Blockade of $V E G F / V E G F R$ signaling drives compensatory mechanisms of tumor vasculogenesis. Increased vascular co-option was seen in $H I F-1 \alpha$ transgenic knockout mice, as well as GBM mouse xenograft models treated with a neutralizing VEGF antibody $(10,97)$. In humans, co-option was observed in resected tumor samples after pre-surgery exposure to bevacizumab or cediranib $(98,99)$. VEGF/VEGFR blockade also leads to de novo blood vessel formation and stabilization via the $V E G F$ independent pathways described above (10,99-106).

Independent of increasing angiogenesis, disease resistance to anti-angiogenic agents may be mediated by other mechanisms of tumor perseverance. The hypoxiainduced pathways above also drive tumor progression through expansion of a $H I F$-regulated tumor progenitor population (107). Tumor cells under hypoxic stress may also evade immediate cell death with autophagy-driven sequestering of damaged cell components, mediated by HIF-1 $\alpha$ and B-cell CLL/lymphoma 2 (BCL2)-interacting protein 3 (BNIP3) (100). In addition to in situ resilience, tumor cells treated with anti-angiogenic agents migrate and invade away from hypoxic areas, demonstrated both in mouse models of GBM $(108,109)$ and in humans $(110,111)$. This invasion is often perivascular in nature along blood vessels remaining after anti-angiogenic treatment, with tumor cells co-opting pre-existing vessels in a $V E G F$ independent manner (97). This invasion is seen on MRI as non-enhancing disease and can be multifocal and thus more difficult to address with focal treatments (surgery, radiation, etc.) at the time of recurrence $(26,101,108)$. This invasive phenotype may be mediated through upregulation of genes that facilitate cellular motility as 


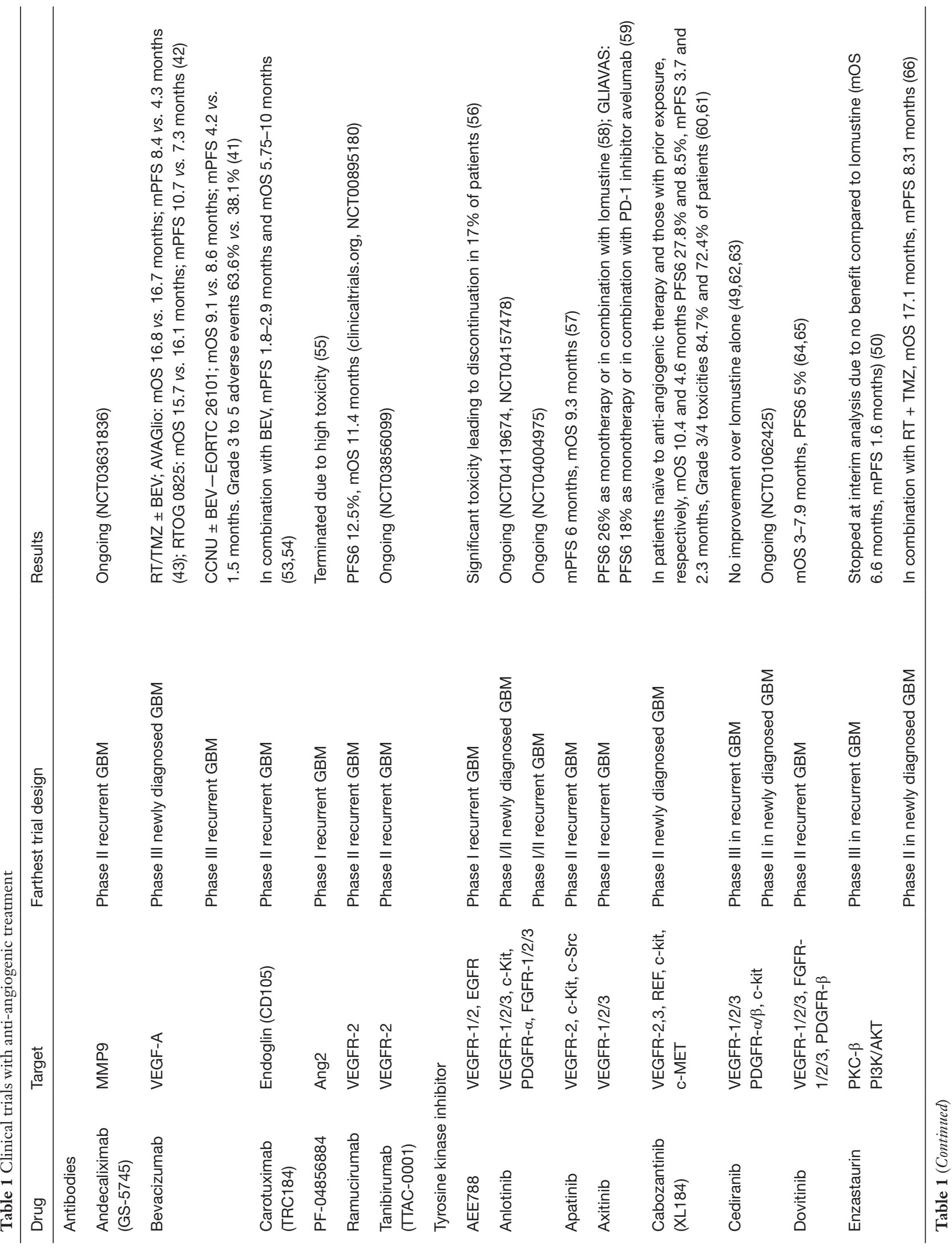




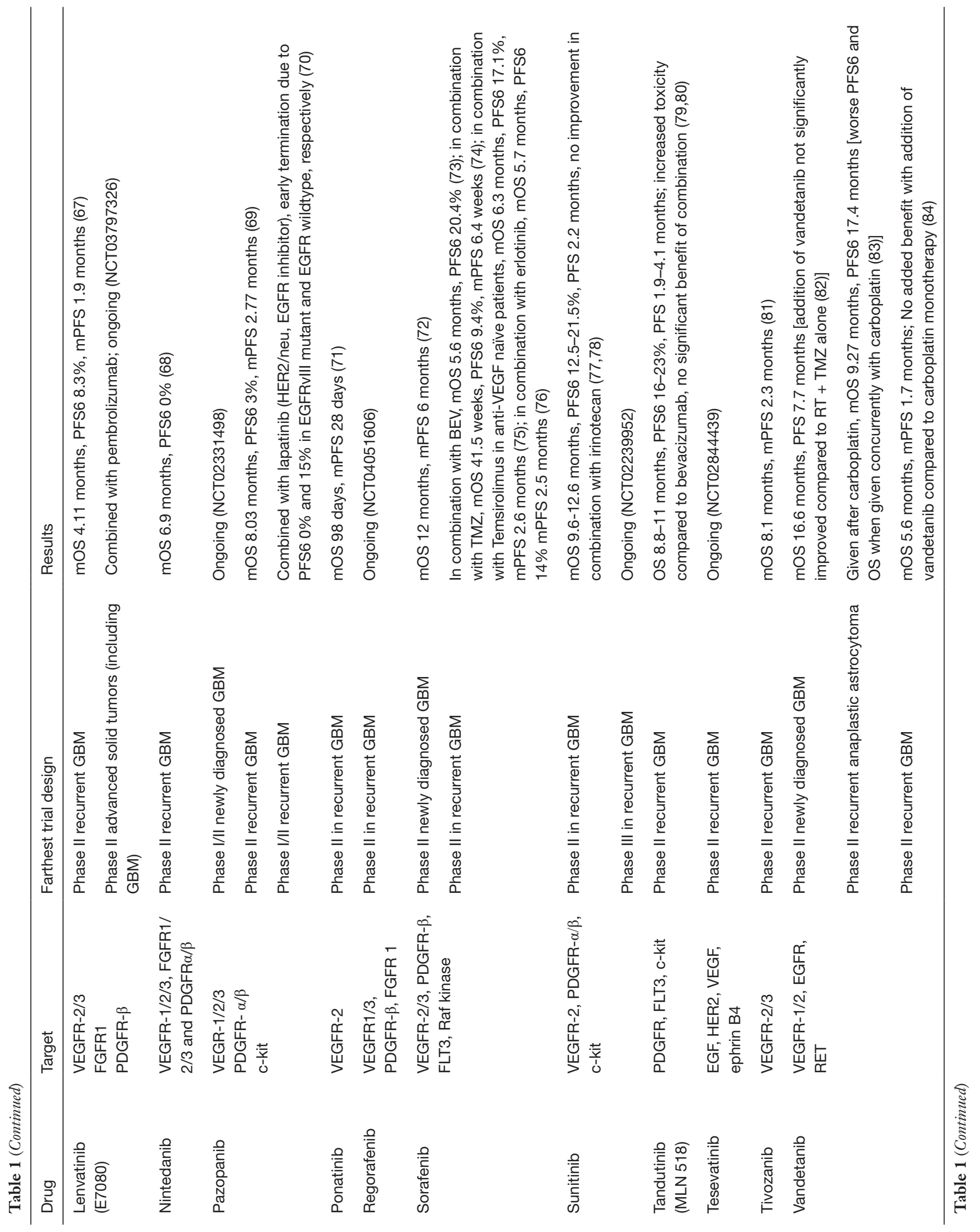




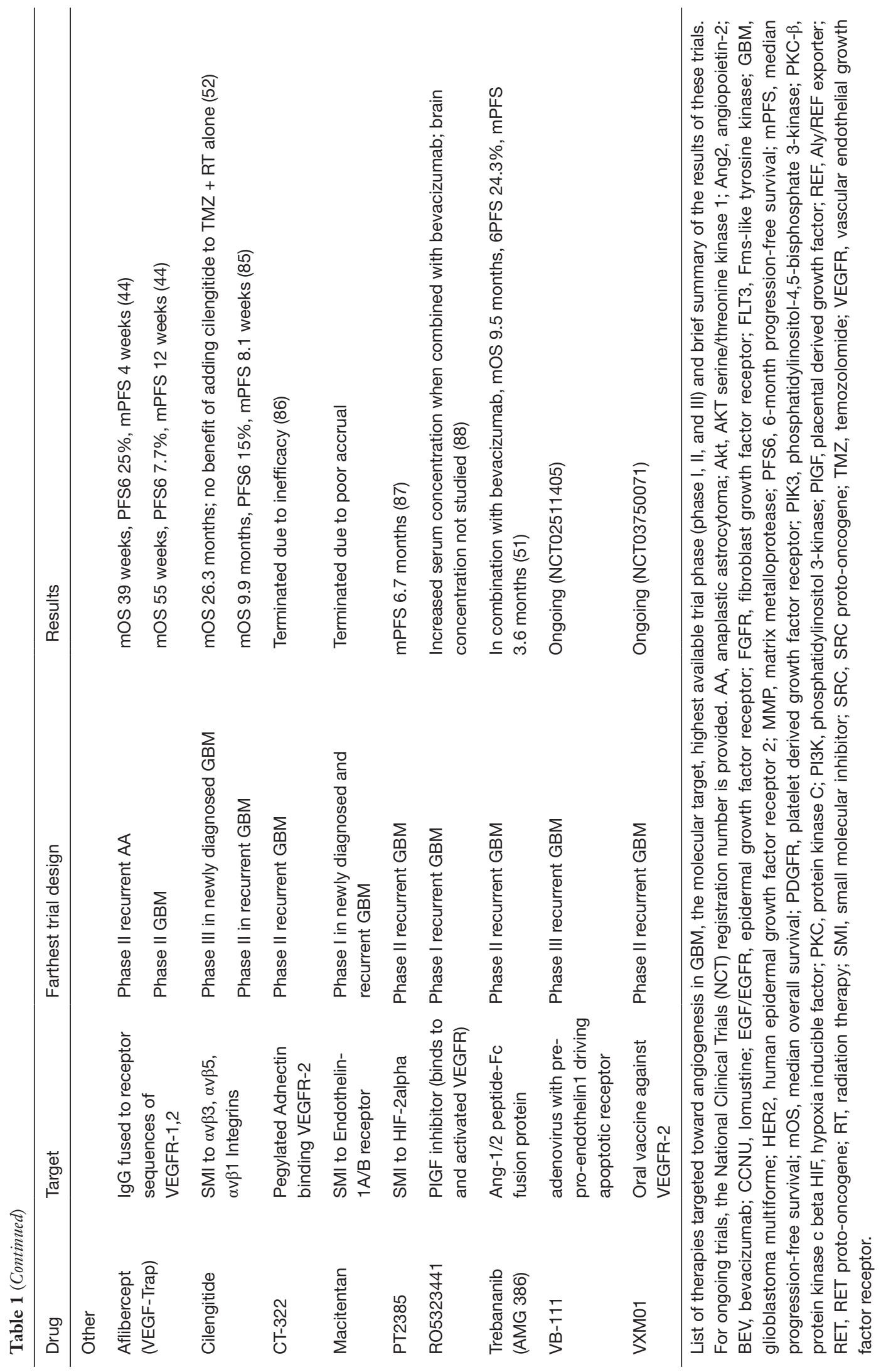




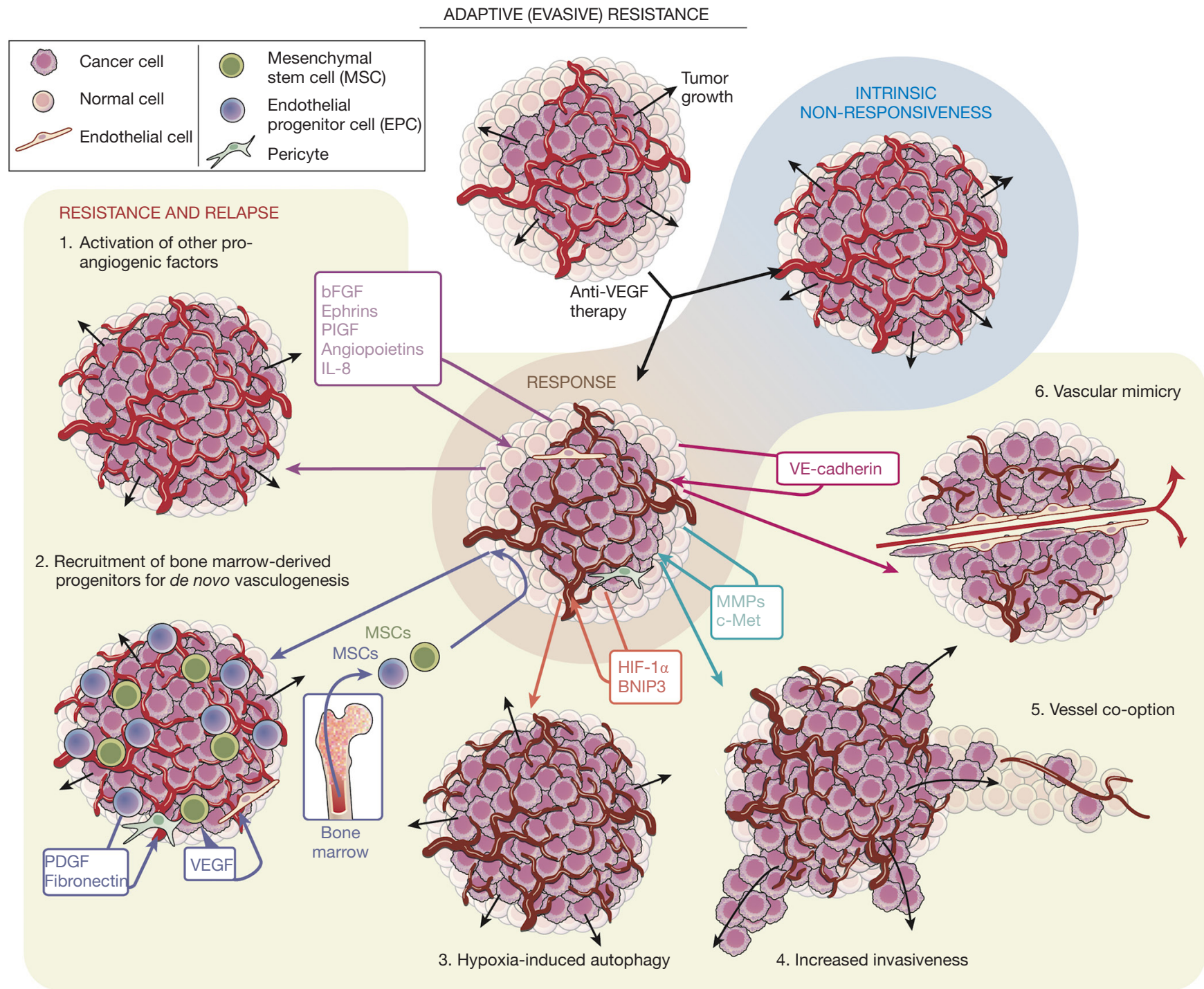

Figure 1 Mechanisms of resistance to anti-VEGF therapy. Resistance to VEGF targeted therapy is multifactorial, involving initial nonresponsiveness of tumor cells to anti-VEGF therapy, as well as later acquired resistance via several mechanisms. [1] Upregulation of angiogenesis through VEGF-independent pathways, including FGF, PlGF, HGF, c-MET, ANG1, ANG2, and interleukins. [2] Increased recruitment of bone-marrow derived progenitors, including mesenchymal stem cells and endothelial progenitor cells, which differentiate into pericytes and endothelial cells, respectively, to populate new blood vessels. [3] Tumor cells under hypoxic stress sequester damaged cell components, in a process called "autophagy", which delays cellular apoptosis. [4] Tumor cells treated with anti-angiogenic agents migrate and invade away from hypoxic areas, making treatment with surgery and radiation more difficult. [5] Tumor cells in hypoxic environments will migrate toward blood vessels in the nearby normal brain, and "co-opt" these vessels for their supply of oxygen and nutrients. [6] Tumor cells can change their shape to resemble endothelial cells, and will aggregate with normal endothelial cells to create cylindrical structures with lumen, which behave as blood vessels. Adapted from Chandra et al. (89). ANG1/2, angiopoietin 1/2; bFGF, basic fibroblast growth factor; BNIP3, B-cell CLL/lymphoma 2 (BCL2)-interacting protein 3; c-MET, c-MET proto-oncogene; HIF-1 $\alpha$, hypoxia inducible factor 1 subunit alpha; HGF, hepatic growth factor; IL-8, interleukin-8; PDGF, platelet-derived growth factor; PlGF, placental growth factor; VEGF, vascular endothelial growth factor; MMP, matrix metalloproteinase; VE-cadherin, vascular endothelial cadherin. 
well as proteins that allow invasion of cells through the extracellular matrix including MMPs -2 , -9 , and -12 ; and secreted protein acidic and rich in cysteine (SPARC) (112). Among other pro-migratory mechanisms, tumor cells may transition to a mesenchymal phenotype mediated via $P D G F$ and HGF-dependent MET signaling $(105,113)$. This was demonstrated after exposure to either bevacizumab or cediranib $(99,114)$, and led to interest in targeting the MET pathway in conjunction with VEGF manipulation, as MET may also contribute to tumor growth. Although a phase II trial evaluating bevacizumab with or without onartuzumab, a monovalent MET inhibitor, failed to improve PFS or OS (115), trials of other c-MET inhibitors are in progress (NCT02386826, NCT02270034).

\section{Evolving use of anti-angiogenic therapy}

Though anti-angiogenic therapies to date have failed to extend survival in new or recurrent GBM, their contribution to PFS suggests some degree of benefit, possibly through alleviation of peritumoral edema (116). Corticosteroids are first line therapy for peritumoral edema, but have a broad and high-frequency side effect profile particularly in the setting of prolonged use, including myopathy, hyperglycemia, weight gain, hypertension, osteoporosis, insomnia, anxiety, and rarely avascular necrosis among other toxicities (117). Bevacizumab carries a distinct range of side effects, including hypertension and poor wound healing, but also rare risks of thromboembolism, hemorrhage, gastrointestinal perforation and nephrotic syndrome (118). Several clinical trials suggested that bevacizumab can reduce reliance on corticosteroids in GBM patients. These observations emerged from the AVF3708g trial, EORTC26101 trial, and other observational studies $(38,39,119)$. Likewise, use of cediranib and cabozantinib (which inhibits VEGF2, MET, AXL tyrosine kinase, and ret protooncogene RET) also correlated with reduced corticosteroid use over time $(60,94)$. In regards to qualityof-life and symptom control, there is conflicting evidence as to whether bevacizumab is beneficial. The AVAglio trial in newly diagnosed GBM noted delayed deterioration of quality-of-life metrics (including global health status, cognitive, emotional, and social functioning, and ability to communicate) with bevacizumab compared to control, and stable Mini Mental Status Examination (43). However, the RTOG0825 study reported decreased quality-of-life measures (symptom control and neurocognitive function) with bevacizumab compared to placebo (42).
Bevacizumab is also used to treat the clinical and radiographic changes associated with radiation necrosis in the brain. Radiation may underlie short- and long-term changes to the vasculature including increased vascular permeability, vasculopathy, ischemia, necrosis, and resultant edema (120). These pathological changes underlie MRI findings including increased contrast enhancement and edema that are often difficult to distinguish from tumor progression. Radiation necrosis can be symptomatic with focal deficits including weakness and aphasia, headaches, and seizures. Recent studies demonstrated bevacizumab to be a powerful tool for managing radiation-associated edema $(121,122)$. There is an ongoing phase II clinical trial comparing corticosteroids plus bevacizumab versus placebo for the treatment of radiation necrosis in brain metastasis (NCT02490878).

In addition to symptomatic treatment, there is still hope that anti-VEGF agents may be helpful in combination with other therapies, including cytotoxic chemotherapy, TKIs, and immunotherapy, in improving survival in GBM. Many of these combinatorial strategies rely on the recent mechanistic understanding that anti-VEGF therapies may act to normalize the blood vasculature, improving spatial and temporal delivery of therapeutic agents across the tumor $(34,123)$. Improved efficacy of combinatory treatment may require specific timing of anti-VEGF agents with cytotoxic/ cytostatic agents. For example, a phase II trial looking at cediranib demonstrated vascular normalization occurs day 1 to 28 after drug dosage (94). Experiments looking at the time frame for vascular normalization after bevacizumab have yet to be been done in GBM, but mouse models suggest it starts as early as 1 day after infusion and clinical trials in rectal carcinoma suggest half of the tumor vasculature is normalized by day 12 (124). The dosing of bevacizumab may influence response as well, with some studies suggesting that a reduced dose may be more efficacious $(125,126)$.

The interaction of VEGF signaling and the immune system is of particular interest given the impact of immunotherapies in several cancers. VEGF signaling inhibits differentiation of circulating hemopoietic progenitor cells, dendritic cells, and $\mathrm{T}$ cells through nuclear factor kappa B $(N F \kappa B)$ signaling $(127,128)$. Aflibercept also increases the mature dendritic cell population in solid tumors (129). In a study of colorectal cancer, bevacizumab increased CD4+ and CD8+ T cells, as well as CD20+ B cells in peripheral blood (130). However, these studies suggesting that VEGF inhibition may alleviate VEGFmediated immunosuppression was countered by a study in 
which VEGF inhibition was tied to impaired lymphocyte recruitment (131). A better understanding of the role of VEGF in regulating the brain immune niche and GBM tumor microenvironment is clearly needed.

\section{Conclusions}

Angiogenesis is a hallmark feature of GBM and the role of anti-angiogenic agents in GBM treatment has evolved over time. While initial trials were promising that these agents could impact prognosis, many agents including antiVEGF antibody failed to prolong survival in both newly diagnosed and recurrent GBM, either as monotherapy or in combination with traditional chemotherapies and other targeted agents. Despite these challenges, antiangiogenic agents still have utility for managing vasogenic and radiation-related edema, being used in combination to target multiple angiogenic pathways, and to promote the intratumoral uptake of other chemotherapies.

\section{Acknowledgments}

Funding: None.

\section{Footnote}

Provenance and Peer Review: This article was commissioned by the Guest Editor (Rimas V. Lukas) for the series "The evolving landscape of the management of glioblastoma" published in Chinese Clinical Oncology. The article was sent for external peer review organized by the Guest Editor and the editorial office.

Conflicts of Interest: All authors have completed the ICMJE uniform disclosure form (available at http://dx.doi. org/10.21037/cco.2020.03.06). JWT reports grants from BMS, grants from Agios, grants from Abbive, all outside the submitted work. The other authors have no conflicts of interest to declare.

Ethical Statement: The authors are accountable for all aspects of the work in ensuring that questions related to the accuracy or integrity of any part of the work are appropriately investigated and resolved.

Open Access Statement: This is an Open Access article distributed in accordance with the Creative Commons Attribution-NonCommercial-NoDerivs 4.0 International
License (CC BY-NC-ND 4.0), which permits the noncommercial replication and distribution of the article with the strict proviso that no changes or edits are made and the original work is properly cited (including links to both the formal publication through the relevant DOI and the license). See: https://creativecommons.org/licenses/by-nc$\mathrm{nd} / 4.0 \%$.

\section{References}

1. Stupp R, Mason WP, van den Bent MJ, et al. Radiotherapy plus concomitant and adjuvant temozolomide for glioblastoma. N Engl J Med 2005;352:987-96.

2. Yan H, Parsons DW, Jin G, et al. IDH1 and IDH2 mutations in gliomas. N Engl J Med 2009;360:765-73.

3. Eckel-Passow JE, Lachance DH, Molinaro AM, et al. Glioma groups based on 1p/19q, IDH, and TERT promoter mutations in tumors. $\mathrm{N}$ Engl $\mathrm{J}$ Med 2015;372:2499-508.

4. Stupp R, Taillibert S, Kanner A, et al. Effect of tumortreating fields plus maintenance temozolomide vs maintenance temozolomide alone on survival in patients with glioblastoma: a randomized clinical trial. JAMA 2017;318:2306-16.

5. Louis DN, Ohgaki H, Wiestler OD, et al. The 2007 WHO classification of tumours of the central nervous system. Acta Neuropathol 2007;114:97-109.

6. Louis DN, Perry A, Reifenberger G, et al. The 2016 World Health Organization Classification of Tumors of the Central Nervous System: a summary. Acta Neuropathol 2016;131:803-20.

7. Calabrese C, Poppleton H, Kocak M, et al. A perivascular niche for brain tumor stem cells. Cancer Cell 2007;11:69-82.

8. Holash J, Maisonpierre PC, Compton D, et al. Vessel cooption, regression, and growth in tumors mediated by angiopoietins and VEGF. Science 1999;284:1994-8.

9. Brem S. The role of vascular proliferation in the growth of brain tumors. Clin Neurosurg 1976;23:440-53.

10. Du R, Lu KV, Petritsch C, et al. HIF1alpha induces the recruitment of bone marrow-derived vascular modulatory cells to regulate tumor angiogenesis and invasion. Cancer Cell 2008;13:206-20.

11. Nico B, Crivellato E, Guidolin D, et al. Intussusceptive microvascular growth in human glioma. Clin Exp Med 2010;10:93-8.

12. Hardee ME, Zagzag D. Mechanisms of glioma-associated neovascularization. Am J Pathol 2012;181:1126-41. 


\section{Page 10 of 14}

13. Wang R, Chadalavada K, Wilshire J, et al. Glioblastoma stem-like cells give rise to tumour endothelium. Nature 2010;468:829-33.

14. Cheng L, Huang Z, Zhou W, et al. Glioblastoma stem cells generate vascular pericytes to support vessel function and tumor growth. Cell 2013;153:139-52.

15. Ricci-Vitiani L, Pallini R, Biffoni M, et al. Tumour vascularization via endothelial differentiation of glioblastoma stem-like cells. Nature 2010;468:824-8.

16. Plate KH, Breier G, Weich HA, et al. Vascular endothelial growth factor is a potential tumour angiogenesis factor in human gliomas in vivo. Nature 1992;359:845-8.

17. Ferrara N, Davis-Smyth T. The biology of vascular endothelial growth factor. Endocr Rev 1997;18:4-25.

18. Suri C, McClain J, Thurston G, et al. Increased vascularization in mice overexpressing angiopoietin-1. Science 1998;282:468-71.

19. Maisonpierre PC, Suri C, Jones PF, et al. Angiopoietin-2, a natural antagonist for Tie2 that disrupts in vivo angiogenesis. Science 1997;277:55-60.

20. Sato TN, Tozawa Y, Deutsch U, et al. Distinct roles of the receptor tyrosine kinases Tie-1 and Tie-2 in blood vessel formation. Nature 1995;376:70-4.

21. Sawamiphak S, Seidel S, Essmann CL, et al. Ephrin-B2 regulates VEGFR2 function in developmental and tumour angiogenesis. Nature 2010;465:487-91.

22. Ridgway J, Zhang G, Wu Y, et al. Inhibition of Dll4 signalling inhibits tumour growth by deregulating angiogenesis. Nature. 2006;444:1083-7.

23. Arany Z, Foo SY, Ma Y, et al. HIF-independent regulation of VEGF and angiogenesis by the transcriptional coactivator PGC-1alpha. Nature 2008;451:1008-12.

24. Parliament MB, Allalunis-Turner MJ, Franko AJ, et al. Vascular endothelial growth factor expression is independent of hypoxia in human malignant glioma spheroids and tumours. Br J Cancer 2000;82:635-41.

25. Kaur S, Martin-Manso G, Pendrak ML, et al. Thrombospondin-1 inhibits VEGF receptor-2 signaling by disrupting its association with CD47. J Biol Chem 2010;285:38923-32.

26. Bloch O, Safaee M, Sun MZ, et al. Disseminated progression of glioblastoma after treatment with bevacizumab. Clin Neurol Neurosurg 2013;115:1795-801.

27. Zheng H, Fu G, Dai T, et al. Migration of endothelial progenitor cells mediated by stromal cell-derived factor1alpha/CXCR4 via PI3K/Akt/eNOS signal transduction pathway. J Cardiovasc Pharmacol 2007;50:274-80.

28. Zagzag D, Lukyanov Y, Lan L, et al. Hypoxia-inducible factor 1 and VEGF upregulate CXCR4 in glioblastoma: implications for angiogenesis and glioma cell invasion. Lab Invest 2006;86:1221-32.

29. Mandriota SJ, Pepper MS. Vascular endothelial growth factor-induced in vitro angiogenesis and plasminogen activator expression are dependent on endogenous basic fibroblast growth factor. J Cell Sci. 1997;110:2293-302.

30. Guo P, Hu B, Gu W, et al. Platelet-derived growth factor-B enhances glioma angiogenesis by stimulating vascular endothelial growth factor expression in tumor endothelia and by promoting pericyte recruitment. Am J Pathol 2003;162:1083-93.

31. Koochekpour S, Merzak A, Pilkington GJ. Vascular endothelial growth factor production is stimulated by gangliosides and TGF-beta isoforms in human glioma cells in vitro. Cancer Lett 1996;102:209-15.

32. Wang D, Huang HJ, Kazlauskas A, et al. Induction of vascular endothelial growth factor expression in endothelial cells by platelet-derived growth factor through the activation of phosphatidylinositol 3-kinase. Cancer Res 1999;59:1464-72.

33. Jain RK, di Tomaso E, Duda DG, et al. Angiogenesis in brain tumours. Nat Rev Neurosci 2007;8:610-22.

34. Jain RK. Normalization of tumor vasculature: an emerging concept in antiangiogenic therapy. Science 2005;307:58-62.

35. Zhou YH, Tan F, Hess KR, et al. The expression of PAX6, PTEN, vascular endothelial growth factor, and epidermal growth factor receptor in gliomas: relationship to tumor grade and survival. Clin Cancer Res 2003;9:3369-75.

36. Chen W, He D, Li Z, et al. Overexpression of vascular endothelial growth factor indicates poor outcomes of glioma: a systematic review and meta-analysis. Int J Clin Exp Med 2015;8:8709-19.

37. Hurwitz H, Fehrenbacher L, Novotny W, et al. Bevacizumab plus irinotecan, fluorouracil, and leucovorin for metastatic colorectal cancer. N Engl J Med 2004;350:2335-42.

38. Friedman HS, Prados MD, Wen PY, et al. Bevacizumab alone and in combination with irinotecan in recurrent glioblastoma. J Clin Oncol 2009;27:4733-40.

39. Kreisl TN, Kim L, Moore K, et al. Phase II trial of single-agent bevacizumab followed by bevacizumab plus irinotecan at tumor progression in recurrent glioblastoma. J Clin Oncol 2009;27:740-5.

40. Vredenburgh JJ, Desjardins A, Herndon JE 2nd, et al. Phase II trial of bevacizumab and irinotecan in recurrent malignant glioma. Clin Cancer Res 2007;13:1253-9. 
41. Wick W, Gorlia T, Bendszus M, et al. Lomustine and Bevacizumab in Progressive Glioblastoma. N Engl J Med 2017;377:1954-63.

42. Gilbert MR, Dignam JJ, Armstrong TS, et al. A randomized trial of bevacizumab for newly diagnosed glioblastoma. N Engl J Med 2014;370:699-708.

43. Chinot OL, Wick W, Mason W, et al. Bevacizumab plus radiotherapy-temozolomide for newly diagnosed glioblastoma. N Engl J Med 2014;370:709-22.

44. de Groot JF, Lamborn KR, Chang SM, et al. Phase II study of aflibercept in recurrent malignant glioma: a North American Brain Tumor Consortium study. J Clin Oncol 2011;29:2689-95.

45. Motzer RJ, Hutson TE, Tomczak P, et al. Overall survival and updated results for sunitinib compared with interferon alfa in patients with metastatic renal cell carcinoma. J Clin Oncol 2009;27:3584-90.

46. Escudier B, Eisen T, Stadler WM, et al. Sorafenib in advanced clear-cell renal-cell carcinoma. N Engl J Med 2007;356:125-34

47. Kreisl TN, Smith P, Sul J, et al. Continuous daily sunitinib for recurrent glioblastoma. J Neurooncol 2013;111:41-8.

48. Hottinger AF, Ben Aissa A, Espeli V, et al. Phase I study of sorafenib combined with radiation therapy and temozolomide as first-line treatment of high-grade glioma. Br J Cancer 2014;110:2655-61.

49. Batchelor TT, Mulholland P, Neyns B, et al. Phase III randomized trial comparing the efficacy of cediranib as monotherapy, and in combination with lomustine, versus lomustine alone in patients with recurrent glioblastoma. J Clin Oncol 2013;31:3212-8.

50. Wick W, Puduvalli VK, Chamberlain MC, et al. Phase III study of enzastaurin compared with lomustine in the treatment of recurrent intracranial glioblastoma. J Clin Oncol 2010;28:1168-74.

51. Reardon DA, Lassman AB, Schiff D, et al. Phase 2 and biomarker study of trebananib, an angiopoietin-blocking peptibody, with and without bevacizumab for patients with recurrent glioblastoma. Cancer 2018;124:1438-48.

52. Stupp R, Hegi ME, Gorlia T, et al. Cilengitide combined with standard treatment for patients with newly diagnosed glioblastoma with methylated MGMT promoter (CENTRIC EORTC 26071-22072 study): a multicentre, randomised, open-label, phase 3 trial. Lancet Oncol 2014;15:1100-8.

53. Ahluwalia MS, Rogers LR, Chaudhary RT, et al. A phase 2 trial of TRC105 with bevacizumab for bevacizumab refractory glioblastoma. J Clin Oncol 2016;34:2035.
54. Galanis E, Anderson SK, Butowski NA, et al. NCCTG N1174: Phase I/comparative randomized phase (Ph) II trial of TRC105 plus bevacizumab versus bevacizumab in recurrent glioblastoma (GBM) (Alliance). J Clin Oncol 2017;35:2023.

55. Gollerkeri A, Gordon M, Burke J, et al. Phase Ib safety trial of CVX-060, an intravenous humanized monoclonal CovX body inhibiting angiopoietin 2 (Ang-2), with axitinib in patients with previously treated metastatic renal cell cancer (RCC). J Clin Oncol 2013;31:2533.

56. Reardon DA, Conrad CA, Cloughesy T, et al. Phase I study of AEE788, a novel multitarget inhibitor of ErbBand VEGF-receptor-family tyrosine kinases, in recurrent glioblastoma patients. Cancer Chemother Pharmacol 2012;69:1507-18.

57. Wang Y, Meng X, Zhou S, et al. Apatinib Plus Temozolomide for Recurrent Glioblastoma: an Uncontrolled, Open-Label Study. Onco Targets Ther 2019;12:10579-85.

58. Duerinck J, Du Four S, Bouttens F, et al. Randomized phase II trial comparing axitinib with the combination of axitinib and lomustine in patients with recurrent glioblastoma. J Neurooncol 2018;136:115-25.

59. Neyns B, Ben Salama L, Awada G, et al. GLIAVAX: A stratified phase II clinical trial of avelumab and axitinib in patients with recurrent glioblastoma. J Clin Oncol 2019;37:2034.

60. Wen PY, Drappatz J, de Groot J, et al. Phase II study of cabozantinib in patients with progressive glioblastoma: subset analysis of patients naive to antiangiogenic therapy. Neuro Oncol 2018;20:249-58.

61. Cloughesy TF, Drappatz J, de Groot J, et al. Phase II study of cabozantinib in patients with progressive glioblastoma: subset analysis of patients with prior antiangiogenic therapy. Neuro Oncol 2018;20:259-67.

62. Batchelor TT, Duda DG, di Tomaso E, et al. Phase II study of cediranib, an oral pan-vascular endothelial growth factor receptor tyrosine kinase inhibitor, in patients with recurrent glioblastoma. J Clin Oncol 2010;28:2817-23.

63. Sorensen AG, Emblem KE, Polaskova P, et al. Increased survival of glioblastoma patients who respond to antiangiogenic therapy with elevated blood perfusion. Cancer Res 2012;72:402-7.

64. Sharma M, Schilero C, Peereboom DM, et al. Phase II study of Dovitinib in recurrent glioblastoma. J Neurooncol 2019;144:359-68.

65. Ahluwalia MS, Papadantonakis N, Alva Venur V, et al. Phase II trial of dovitinib in recurrent glioblastoma. J Clin 
Oncol 2015;33:2050.

66. Butowski N, Chang SM, Lamborn KR, et al. Phase II and pharmacogenomics study of enzastaurin plus temozolomide during and following radiation therapy in patients with newly diagnosed glioblastoma multiforme and gliosarcoma. Neuro Oncol 2011;13:1331-8.

67. Reardon DA, Pan E, Fan J, et al. A phase 2 trial of the multitargeted kinase inhibitor lenvatinib (E7080) in patients (PTS) with recurrent glioblastoma (GBM) and disease progression following prior bevacizumab treatment. Ann Oncol 2012;23:ix146.

68. Norden AD, Schiff D, Ahluwalia MS, et al. Phase II trial of triple tyrosine kinase receptor inhibitor nintedanib in recurrent high-grade gliomas. J Neurooncol 2015;121:297-302.

69. Iwamoto FM, Lamborn KR, Robins HI, et al. Phase II trial of pazopanib (GW786034), an oral multitargeted angiogenesis inhibitor, for adults with recurrent glioblastoma (North American Brain Tumor Consortium Study 06-02). Neuro Oncol 2010;12:855-61.

70. Reardon DA, Groves MD, Wen PY, et al. A phase I/II trial of pazopanib in combination with lapatinib in adult patients with relapsed malignant glioma. Clin Cancer Res 2013;19:900-8.

71. Lee EQ, Muzikansky A, Duda DG, et al. Phase II trial of ponatinib in patients with bevacizumab-refractory glioblastoma. Cancer Med 2019;8:5988-94.

72. Hainsworth JD, Ervin T, Friedman E, et al. Concurrent radiotherapy and temozolomide followed by temozolomide and sorafenib in the first-line treatment of patients with glioblastoma multiforme. Cancer 2010;116:3663-9.

73. Galanis E, Anderson SK, Lafky JM, et al. Phase II study of bevacizumab in combination with sorafenib in recurrent glioblastoma (N0776): a north central cancer treatment group trial. Clin Cancer Res 2013;19:4816-23.

74. Reardon DA, Vredenburgh JJ, Desjardins A, et al. Effect of CYP3A-inducing anti-epileptics on sorafenib exposure: results of a phase II study of sorafenib plus daily temozolomide in adults with recurrent glioblastoma. J Neurooncol 2011;101:57-66.

75. Schiff D, Jaeckle KA, Anderson SK, et al. Phase 1/2 trial of temsirolimus and sorafenib in the treatment of patients with recurrent glioblastoma: North Central Cancer Treatment Group Study/Alliance N0572. Cancer 2018;124:1455-63.

76. Peereboom DM, Ahluwalia MS, Ye X, et al. NABTT 0502: a phase II and pharmacokinetic study of erlotinib and sorafenib for patients with progressive or recurrent glioblastoma multiforme. Neuro Oncol 2013;15:490-6.

77. Reardon DA, Vredenburgh JJ, Coan A, et al. Phase I study of sunitinib and irinotecan for patients with recurrent malignant glioma. J Neurooncol 2011;105:621-7.

78. Hutterer M, Nowosielski M, Haybaeck J, et al. A single-arm phase II Austrian/German multicenter trial on continuous daily sunitinib in primary glioblastoma at first recurrence (SURGE 01-07). Neuro Oncol 2014;16:92-102.

79. Batchelor TT, Gerstner ER, Ye X, et al. Feasibility, phase I, and phase II studies of tandutinib, an oral plateletderived growth factor receptor- $\beta$ tyrosine kinase inhibitor, in patients with recurrent glioblastoma. Neuro Oncol 2017;19:567-75.

80. Odia Y, Sul J, Shih JH, et al. A Phase II trial of tandutinib (MLN 518) in combination with bevacizumab for patients with recurrent glioblastoma. CNS Oncol 2016;5:59-67.

81. Kalpathy-Cramer J, Chandra V, Da X, et al. Phase II study of tivozanib, an oral VEGFR inhibitor, in patients with recurrent glioblastoma. J Neurooncol 2017;131:603-10.

82. Lee EQ, Kaley TJ, Duda DG, et al. A multicenter, phase II, randomized, noncomparative clinical trial of radiation and temozolomide with or without vandetanib in newly diagnosed glioblastoma patients. Clin Cancer Res 2015;21:3610-8.

83. Ambady P, Warren K, Shih J, et al. AT-04: A randomized phase II trial of vandetanib in combination with carboplatin versus carboplatin alone followed by vandetanib alone in adults with recurrent anaplastic astrocytoma. Neuro Oncol 2014;16:v8-9.

84. McNeill K, Iwamoto F, Kreisl T, et al. AT-39: A randomized phase II trial of vandetanib (ZD6474) in combination with carboplatin versus carboplatin alone in adults with recurrent glioblastoma. Neuro Oncol 2014;16:v17.

85. Reardon DA, Fink KL, Mikkelsen T, et al. Randomized phase II study of cilengitide, an integrin-targeting arginine-glycine-aspartic acid peptide, in recurrent glioblastoma multiforme. J Clin Oncol 2008;26:5610-7.

86. Schiff D, Kesari S, de Groot J, et al. Phase 2 study of CT322, a targeted biologic inhibitor of VEGFR-2 based on a domain of human fibronectin, in recurrent glioblastoma. Invest New Drugs 2015;33:247-53.

87. Strowd RE, Ellingson BM, Wen PY, et al. Safety and activity of a first-in-class oral HIF2-alpha inhibitor, PT2385, in patients with first recurrent glioblastoma (GBM). J Clin Oncol 2019;37:2027.

88. Wang K, Stark FS, Schlothauer T, et al. An apparent 
clinical pharmacokinetic drug-drug interaction between bevacizumab and the anti-placental growth factor monoclonal antibody RO5323441 via a targettrapping mechanism. Cancer Chemother Pharmacol 2017;79:661-71.

89. Chandra A, Rick J, Yagnik G, et al. Autophagy as a mechanism for anti-angiogenic therapy resistance. Semin Cancer Biol 2020;66:75-88.

90. Lynch TJ, Bell DW, Sordella R, et al. Activating mutations in the epidermal growth factor receptor underlying responsiveness of non-small-cell lung cancer to gefitinib. N Engl J Med 2004;350:2129-39.

91. Gacche RN. Compensatory angiogenesis and tumor refractoriness. Oncogenesis 2015;4:e153.

92. Bergers G, Hanahan D. Modes of resistance to antiangiogenic therapy. Nat Rev Cancer 2008;8:592-603.

93. Simon MP, Tournaire R, Pouyssegur J. The angiopoietin-2 gene of endothelial cells is up-regulated in hypoxia by a HIF binding site located in its first intron and by the central factors GATA-2 and Ets-1. J Cell Physiol 2008;217:809-18.

94. Batchelor TT, Sorensen AG, di Tomaso E, et al. AZD2171, a pan-VEGF receptor tyrosine kinase inhibitor, normalizes tumor vasculature and alleviates edema in glioblastoma patients. Cancer Cell 2007;11:83-95.

95. Yu P, Wilhelm K, Dubrac A, et al. FGF-dependent metabolic control of vascular development. Nature 2017;545:224-8

96. Li JL, Sainson RC, Oon CE, et al. DLL4-Notch signaling mediates tumor resistance to anti-VEGF therapy in vivo. Cancer Res 2011;71:6073-83.

97. Rubenstein JL, Kim J, Ozawa T, et al. Anti-VEGF antibody treatment of glioblastoma prolongs survival but results in increased vascular cooption. Neoplasia 2000;2:306-14.

98. Tamura R, Tanaka T, Miyake K, et al. Histopathological investigation of glioblastomas resected under bevacizumab treatment. Oncotarget 2016;7:52423-35.

99. di Tomaso E, Snuderl M, Kamoun WS, et al. Glioblastoma recurrence after cediranib therapy in patients: lack of "rebound" revascularization as mode of escape. Cancer Res 2011;71:19-28.

100.Hu YL, DeLay M, Jahangiri A, et al. Hypoxia-induced autophagy promotes tumor cell survival and adaptation to antiangiogenic treatment in glioblastoma. Cancer Res 2012;72:1773-83.

101.Iwamoto FM, Abrey LE, Beal K, et al. Patterns of relapse and prognosis after bevacizumab failure in recurrent glioblastoma. Neurology 2009;73:1200-6.

102. Jin DK, Shido K, Kopp HG, et al. Cytokine-mediated deployment of SDF-1 induces revascularization through recruitment of CXCR4+ hemangiocytes. Nat Med 2006;12:557-67.

103. Crawford Y, Kasman I, Yu L, et al. PDGF-C mediates the angiogenic and tumorigenic properties of fibroblasts associated with tumors refractory to anti-VEGF treatment. Cancer Cell 2009;15:21-34.

104.di Tomaso E, London N, Fuja D, et al. PDGF-C induces maturation of blood vessels in a model of glioblastoma and attenuates the response to anti-VEGF treatment. PLoS One 2009;4:e5123.

105.Liu T, Ma W, Xu H, et al. PDGF-mediated mesenchymal transformation renders endothelial resistance to antiVEGF treatment in glioblastoma. Nat Commun 2018;9:3439.

106. Song N, Huang Y, Shi H, et al. Overexpression of plateletderived growth factor-BB increases tumor pericyte content via stromal-derived factor-1alpha/CXCR4 axis. Cancer Res 2009;69:6057-64.

107.Li Z, Bao S, Wu Q, et al. Hypoxia-inducible factors regulate tumorigenic capacity of glioma stem cells. Cancer Cell 2009;15:501-13.

108.Pàez-Ribes M, Allen E, Hudock J, et al. Antiangiogenic therapy elicits malignant progression of tumors to increased local invasion and distant metastasis. Cancer Cell 2009; 15:220-31.

109.Ebos JM, Lee CR, Kerbel RS. Tumor and hostmediated pathways of resistance and disease progression in response to antiangiogenic therapy. Clin Cancer Res 2009;15:5020-5.

110. de Groot JF, Fuller G, Kumar AJ, et al. Tumor invasion after treatment of glioblastoma with bevacizumab: radiographic and pathologic correlation in humans and mice. Neuro Oncol 2010;12:233-42.

111. Norden AD, Young GS, Setayesh K, et al. Bevacizumab for recurrent malignant gliomas: efficacy, toxicity, and patterns of recurrence. Neurology 2008;70:779-87.

112.Lucio-Eterovic AK, Piao Y, de Groot JF. Mediators of glioblastoma resistance and invasion during antivascular endothelial growth factor therapy. Clin Cancer Res 2009; 15:4589-99.

113.Lu KV, Chang JP, Parachoniak CA, et al. VEGF inhibits tumor cell invasion and mesenchymal transition through a MET/VEGFR2 complex. Cancer Cell 2012;22:21-35.

114.Jahangiri A, De Lay M, Miller LM, et al. Gene expression profile identifies tyrosine kinase c-Met as a targetable 
mediator of antiangiogenic therapy resistance. Clin Cancer Res 2013;19:1773-83.

115. Cloughesy T, Finocchiaro G, Belda-Iniesta C, et al. Randomized, double-blind, placebo-controlled, multicenter phase II study of onartuzumab plus bevacizumab versus placebo plus bevacizumab in patients with recurrent glioblastoma: efficacy, safety, and hepatocyte growth factor and O6-methylguanineDNA methyltransferase biomarker analyses. J Clin Oncol 2017;35:343-51.

116. Kaley T, Nolan C, Carver A, et al. Bevacizumab for acute neurologic deterioration in patients with glioblastoma. CNS Oncol 2013;2:413-8.

117. Merck \& Co., Inc. Decadron Labeling-Package Insert. 2019. Available online: https://www.accessdata.fda.gov/ drugsatfda_docs/label/2019/011664s064lbl.pdf

118. Genentech, Inc. Avastin (Bevacizumab) Labeling-Package Insert. 2011. Available online: https://www.accessdata.fda. gov/drugsatfda_docs/label/2011/125085s225lbl.pdf

119. Gramatzki D, Roth P, Rushing EJ, et al. Bevacizumab may improve quality of life, but not overall survival in glioblastoma: an epidemiological study. Ann Oncol 2018;29:1431-6.

120. Schultheiss TE, Kun LE, Ang KK, et al. Radiation response of the central nervous system. Int J Radiat Oncol Biol Phys 1995;31:1093-112.

121.Levin VA, Bidaut L, Hou P, et al. Randomized doubleblind placebo-controlled trial of bevacizumab therapy for radiation necrosis of the central nervous system. Int J Radiat Oncol Biol Phys 2011;79:1487-95.

122. Tye K, Engelhard HH, Slavin KV, et al. An analysis of radiation necrosis of the central nervous system treated with bevacizumab. J Neurooncol 2014;117:321-7.

Cite this article as: Schulte JD, Aghi MK, Taylor JW. Antiangiogenic therapies in the management of glioblastoma. Chin Clin Oncol 2021;10(4):37. doi: 10.21037/cco.2020.03.06
123.Jain RK. Normalizing tumor vasculature with antiangiogenic therapy: a new paradigm for combination therapy. Nat Med 2001;7:987-9.

124. Willett CG, Boucher Y, di Tomaso E, et al. Direct evidence that the VEGF-specific antibody bevacizumab has antivascular effects in human rectal cancer. Nat Med 2004;10:145-7.

125.Lorgis V, Maura G, Coppa G, et al. Relation between bevacizumab dose intensity and high-grade glioma survival: a retrospective study in two large cohorts. J Neurooncol 2012;107:351-8.

126.Levin VA, Mendelssohn ND, Chan J, et al. Impact of bevacizumab administered dose on overall survival of patients with progressive glioblastoma. J Neurooncol 2015;122:145-50.

127. Gabrilovich DI, Chen HL, Girgis KR, et al. Production of vascular endothelial growth factor by human tumors inhibits the functional maturation of dendritic cells. Nat Med 1996;2:1096-103.

128. Ohm JE, Gabrilovich DI, Sempowski GD, et al. VEGF inhibits T-cell development and may contribute to tumorinduced immune suppression. Blood 2003;101:4878-86.

129. Fricke I, Mirza N, Dupont J, et al. Vascular endothelial growth factor-trap overcomes defects in dendritic cell differentiation but does not improve antigen-specific immune responses. Clin Cancer Res 2007;13:4840-8.

130. Manzoni M, Rovati B, Ronzoni M, et al. Immunological effects of bevacizumab-based treatment in metastatic colorectal cancer. Oncology 2010;79:187-96.

131.Zhang J, Silva T, Yarovinsky T, et al. VEGF blockade inhibits lymphocyte recruitment and ameliorates immunemediated vascular remodeling. Circ Res 2010;107:408-17. 